\title{
0 particular e o universal mediados pela tradição
}

\author{
MARIA FRANCISCA PINHEIRO COELHO
}

RESUMO: O texto resenha Leituras brasileiras: itinerários no pensamento social e na literatura, de Mariza Veloso e Angélica Madeira (São Paulo, Paz e Terra, 1999).

PALAVRAS-CHAVE: universalismo, particularismo, cultura, nacionalismo, tradição. entendimento de que "para ser universal é preciso conhecer sua aldeia", postulado caro à literatura, serve também como axioma para as ciências sociais e orienta o livro Leituras brasileiras: itinerários no pensamento social e na literatura, de Mariza Veloso e Angélica Madeira. Com a postura dos modernistas brasileiros para quem o universal deve ser atingido pelo particular e manifesta na frase de Mário de Andrade "precisamos ser nacionais, para que possamos ser universais" - as autoras adiantam sua posição epistemológica no debate da relação universalismo x relativism, globalismo x localismo. Elas não adotam essas categorias como dicotômicas e excludentes e, dessa forma, obtêm ferramenta principal para ir ao âmago das questões.

O vínculo entre o particular e o universal é estabelecido por meio da tradição. Não buscam na tradição acomodação ou nostalgia do passado, mas compreensão do presente e possibilidade de mudança. Em Walter
Professora do Departamento de Sociologia do ICS-UnB 
Benjamin sintetizam suas aspirações: "Em cada época deve-se fazer a tentativa de arrancar a tradição do campo do conformismo, que está sempre prestes a subjugá-la". Cada presente deve reconhecer-se no passado de que é contemporâneo.

A atualidade do trabalho de Mariza Veloso e Angélica Madeira revela-se na leitura contemporânea de clássicos da literatura brasileira como Machado de Assis, Euclides da Cunha, Lima Barreto, Mário de Andrade, Gilberto Freyre e Sérgio Buarque de Holanda. Mergulham no passado em busca da compreensão do momento histórico e do campo intelectual de produção dos autores e de obras literárias alternativas. Procuram identificar os ideais, os valores e as categorias explicativas que influenciaram a produção desses autores e suas diferenças.

Como suporte teórico à compreensão de cada período histórico, as autoras se valem do conceito de epistéme, de Michel Foucault, um conjunto de saberes existentes em determinado momento histórico demarcado por um a priori histórico específico, que organiza e torna possível a existência de vários discursos e práticas sociais. São auxiliadas também pelo conceito de campo intelectual de Pierre Bourdieu, estruturante das posições que os intelectuais ocupam no próprio espaço de atuação, marcado por hierarquias e disputas por posição e prestígio, com regras e instâncias de legitimação específicas. Utilizam o conceito de intertextualidade, de Julia Kristeva, pelo qual a narrativa, implícita ou explicitamente, é sempre uma "réplica", um diálogo que se estabelece com uma ou várias tradições.

Que vêm a ser as "Leituras Brasileiras" que as autoras escolhem como título da obra? A palavra leitura é usada como discurso sobre uma realidade, como representação social. Veloso e Madeira procuram compreender essas "leituras" ou interpretações sobre a sociedade brasileira, assumindo-se também como produtoras de um discurso analítico de obras literárias. Explicam elas: "Partimos do pressuposto de que os discursos não são entidades neutras e estáticas, e compartilhamos a convicção daqueles que os consideram como dotados de produtividade política, de uma capacidade de formatar realidades. Compreendemos cada narrativa sem juízo prévio de valor, tentando captá-la em sua inteireza, em seu tempo e em sua irredutibilidade. Buscamos também inseri-la em sua série, como um ponto de um diagrama perpassado pela história e pela cultura. Por isso, escolhemos narrativas eloqüentes, histórias legíveis e construídas pelos discursos hegemônicos, e também histórias alternativas, em que se mostram outros pontos de vista, suscetíveis de provocar uma descentralização da perspectiva, uma releitura do tempo histórico" (p. 35). Estabelecem vínculo com um objeto particular, a produção literária brasileira, e passam a reconstruir a cultura e a redesenhar o Brasil.

O livro contém visão geral da cultura brasileira dos séculos XIX e $\mathrm{XX}$ e detém-se no enfoque de autores e obras. As narrativas do século XIX são divididas em dois momentos. No primeiro, as que são constituídas pela influência do "olhar estrangeiro" e pelo retrato do homem nativo, modelado pelo tipo ideal do fidalgo, do colonizador. No segundo, a partir da segunda 
metade do século, a idéia de nação passa a ser discutida por meio das noções de raça e meio geográfico. Há destaque na transição do século XIX para o XX, em que sobressaem as obras de Machado de Assis, Euclides da Cunha e Lima Barreto. Nesse momento, é visível o papel desempenhado pela Academia Brasileira de Letras, fundada em 1897, na padronização dos valores da linguagem e na delimitação canônica do campo intelectual.

No século XX, a análise centra-se na produção do Movimento Modernista na literatura e nas ciências sociais. São dedicados ensaios a Mário de Andrade e às obras Casa-grande e senzala, de Gilberto Freyre, e Raízes do Brasil, de Sérgio Buarque de Holanda.

Na última parte do livro, abrangendo dos anos quarenta aos dias atuais, são abordados os modelos explicativos que influenciaram as ciências sociais e os debates intelectuais contemporâneos: o multiculturalismo e a globalização.

Outro propósito consiste em levantar as categorias imanentes às próprias narrativas que influenciaram a construção de um retrato do Brasil. As categorias da primeira metade do século XIX, pátria, povo, língua e território são substituídas na segunda metade do século pelas categorias de raça e meio geográfico. A partir dos anos 20 do século XX, essas categorias são superadas pelas de cultura, civilização e história. Na segunda metade deste século, há proliferação de modelos explicativos e de novas categorias como modernização, dependência, desenvolvimentismo, imperialismo, cultura popular e globalização.

O livro tem momentos de descontração quando trata da irreverência do Movimento Modernista em busca das raízes nacionais, dando novo tratamento à tradição e reescrevendo a cultura brasileira, do particular ao universal, buscando autenticidade e autonomia. Um dos propósitos era renovar a língua literária, aproximando-a da fala.

No diálogo com antepassados, Mário de Andrade recriou e ampliou os tipos brasileiros. Não mais Y-Juca Pirama, de Gonçalves Dias, nem o bem-comportado Pery, de José de Alencar, modelados segundo o bomselvagem de Rousseau, mas o Macunaíma, o herói sem caráter, com sua inventividade e sua magia. Os escritos de Mário de Andrade são críticos à visão do passado, como o Curemos o Pery, em que o autor lança o nacionalismo estético visando problematizar a cultura do povo brasileiro por meio da produção artística; e A escrava que não é Isaura, em que proclama a atitude libertadora dos artistas de seu tempo. O Movimento Modernista recria o Brasil, questiona o retrato projetado pelo "olhar do estrangeiro", tritura-o e aplica-lhe a técnica do antropofagismo, que visa proclamar o olhar do próprio país sobre sua cultura e identidade, em primeira instância.

O prefácio de Sérgio Paulo Rouanet faz a exegese do texto e das fronteiras teóricas utilizadas pelas autoras. Constrói uma leitura própria da temática apresentada. "A impressão que tenho é que as autoras, sem o dizerem de modo explícito, trabalharam com uma teoria da objetividade em dois níveis, o da vigência e o da validade" (p. 16). A vigência tem a ver com a gênese dos discursos e narrativas, com o conjunto de condições que 
fazem com que uma teoria exista, produza efeitos e entre em declínio, e a validade, com a verdade. Embora as autoras não tenham tematizado a diferença entre vigência e validade, ela é, segundo Rouanet, pressuposta em cada linha do livro.

"Leituras Brasileiras" porta mensagem reformadora de volta ao passado para reinventar o futuro: "O conhecimento do que somos e a consciência crítica de nossa formação social e de nossa história devem servir de aliados para o enfrentamento dos desafios contemporâneos" (p. 29). Nesse aspecto, as autoras demonstram identidade com o conteúdo inovador dos modernistas. Recorrem à utilidade da metáfora antropofágica - instrumento de seleção das influências estrangeiras - para lidar com a globalização, selecionando o desejado e o indesejável. "Mais do que nunca, a metáfora antropofágica mantém sua pertinência, quando a categoria da "globalização" parece enquadrar os novos movimentos sociais e deslocamentos no campo da cultura. Na atualidade, quando ocorre uma inflação de mercadorias, signos e informações, a estratégia antropofágica ainda parece útil. Seletiva e ágil, a antropofagia abriu para a cultura brasileira a possibilidade permanente de deglutir e recriar repertórios locais e transnacionais. Tal estratégia pode ainda garantir a permanência da utopia de um acesso público generalizado ao acervo dos bens coletivos, pertencentes à sociedade brasileira" (p. 109).

É a luta do particular para atingir o universal. A esta linha de interpretação do livro poder-se-ia acrescentar que a metáfora antropofágica deveria servir não apenas para combater a influência indesejada da cultura estrangeira, mas também do lixo cultural brasileiro.

Lidar com a tradição não é tarefa fácil. Mariza Veloso e Angélica Madeira sabem. O nacionalismo é um conceito ambíguo e portador de ideologias autoritárias e excludentes. O nacionalismo pregado pelos modernistas teve o sentido libertador do "olhar do estrangeiro" e de valorização da cultura nativa. Mas aprender com a tradição - até para poder negá-la - talvez seja o melhor caminho para dizer aquilo com que nos reconhecemos e o que não nos é contemporâneo.

Em alguns casos, a ausência de tradição pode propiciar também vantagens: como olhar o passado sem o fardo e a orientação de qualquer testamento e dispor de experiências presentes e lidar com elas sem prescrições. Contudo, "Leituras Brasileiras" não problematiza essa questão. Prefere realçar aspectos positivos da tradição.

O desapego ao passado pode proporcionar pensar o presente como é e sentir-se livre para começar o novo; projetar o futuro com o sentimento e a responsabilidade de escolhas próprias, com o exercício da vontade - do eu quero -, sem testamentos a priori. Como seres historicamente condicionados, pode-se pensar não ser isso possível, mas começar é uma capacidade humana, própria da natalidade, categoria tão cara ao pensamento de Hannah Arendt. "O começo, antes de tornar-se evento histórico, é a suprema capacidade do homem; politicamente, equivale à liberdade do homem" (Arendt, 1989, p. 531). Cada novo nascimento garante esse 
COELHO, Maria Francisca Pinheiro. O particular e o universal mediados pela tradição. Tempo Social; Rev. Sociol. USP, S. Paulo, 12(2): 257-261, novembro de 2000.

começo. Sentir-se obrigado à tradição ou desobrigado dela não é bom ou mau, porque a tradição não contém em si uma verdade.

Recebido para publicação em agosto/2000

COELHO, Maria Francisca Pinheiro. The particular and the universal mediated by tradition. Tempo Social; Rev. Sociol. USP. S. Paulo, 12(2):257-261, November 2000.

ABSTRACT: This text is a review of Leituras brasileiras: itinerários no pensamento social e na literatura by Mariza Veloso \& Angélica Madeira (São Paulo, Paz e Terra, 1999).

KEY WORDS: universalism, particularism, culture, nationalism, tradition.

\section{REFERÊNCIASBIBUOGRÁFICAS}

ARENDT, Hannah. (1989) Origens do totalitarismo. São Paulo, Companhia das Letras. 